\title{
Comment by the Board of the German IVF Register on the Article "The German IVF Register as an Instrument to Document Assisted Reproductive Technologies" by S. Kadi and U. Wiesing
}

\author{
Kommentar des Vorstands des Deutschen IVF-Registers zum Artikel „Das Deutsche IVF-Register als Instrument zur \\ Dokumentation der assistierten Reproduktionstechnologien“ von S. Kadi und U. Wiesing
}

Authors

Affiliations

\section{J.-S. Krüssel ${ }^{1}$, A. Tandler-Schneider ${ }^{2}$, U. Czeromin ${ }^{3}$}

${ }^{1}$ Universitäres interdisziplinäres Kinderwunschzentrum Düsseldorf (UniKiD), Universitäts-Frauenklinik, Heinrich-Heine Universität, Düsseldorf

${ }^{2}$ Fertility Center Berlin, Berlin

${ }^{3}$ Kinderwunschpraxis Gelsenkirchen, Gelsenkirchen
Deutsche Version unter: http://dx.doi.org/ $10.1055 / \mathrm{s}-0042-108695$
Bibliography

Dol http://dx.doi.org/

$10.1055 / \mathrm{s}-0042-108695$

Geburtsh Frauenheilk 2016; 76:

685-687 @ Georg Thieme

Verlag KG Stuttgart · New York . ISSN 0016-5751

\section{Correspondence}

Prof. Dr. med. Jan-Steffen Krüssel

Universitäres interdisziplinäres Kinderwunschzentrum Düsseldorf (UniKiD)

Universitäts-Frauenklinik Heinrich-Heine Universität Moorenstraße 5, Geb. 14.75 40225 Düsseldorf kruessel@uni-duesseldorf.de
The authors would like to thank the Editors of the scientific journal "Geburtshilfe und Frauenheilkunde" for giving them the opportunity to write and publish this comment on the article by Kadi and Wiesing.

The article "The German IVF Register as an Instrument to Document Assisted Reproductive Technologies" by Kadi and Wiesing takes a critical look at the structure and work of the German IVF Register (D.I.R). The main issues criticized in their article are:

1. The Register does not have data from all the IVF centers in Germany.

2. The datasets on fertility procedures reported to the German IVF Register are incomplete.

3. Collection of data is not exclusively prospective.

4. The Register only publishes average data for all of Germany and does not publish center-specific data.

5. The presentation of the data is consistently unsuitable for use by non-specialists.

Although the first four criticisms are not altogether wrong, in the opinion of the Board of the D.I.R the overall situation is significantly less critical than portrayed in the article.

The German IVF Register was set up in 1982 by various working groups, all of which were part of university institutions at the time. The fact that, at a time when no legal regulations existed, these working groups recognized the necessity for data to be collected and analyzed centrally and also that they carried out this work voluntarily and of their own accord cannot be praised highly enough. Since then, the D.I.R has existed not just as a voluntary, self-motivated instrument for medical quality assurance but also as the largest data collection on assisted reproductive procedures in Germany. It should also be emphasized that the D.I.R is financed through voluntary contributions paid by centers of reproductive medicine; the centers are currently (as at 2016) invoiced the sum of $€ 2.20$ per documented treat- ment cycle. The work of the elected members of the Board and of the members of the Board of Trustees is entirely unpaid.

On the occasion of the 10th anniversary of the founding of the D.I.R, a former member of the Board stated: "The foremost task of the German IVF Register is to provide a faithful description of procedures carried out using assisted reproductive technologies in Germany and their outcomes" [1]. The D.I.R tries to satisfy these high aspirations. Inevitably, of course, the description and evaluation of procedures and their outcomes can only be as good as the collected data. In this respect, the criticism of Kadi and Wiesing about the incompleteness of the collected data is not unfounded and the Board of the D.I.R is fully aware of this.

It should be noted, however, that since the incorporation of the D.I.R as a registered association in 2009 and despite the termination of the agreements on data assessment between IVF centers and the Medical Association of Schleswig-Holstein (ÄK-SH) by the ÄK-SH in 2013, the percentage of participating centers remains extremely high. Out of a total of 132 IVF centers known to us in Germany, 131 centers (99.2\%) are members of the D.I.R.; 128 of these centers submitted data to the D.I.R (i.e., $97.7 \%$ of all members or $97.0 \%$ of all centers). The three member centers which did not submit their data to the D.I.R were unable to export their data because of compatibility problems with the data capture software at the time of data export. But the data has been collected by the centers, and the centers will soon pass on this data, which will then be included in the 2015 evaluation. This means that the D.I.R will then have collected data on $>99 \%$ of IVF, ICSI and cryo transfer procedures carried out in Germany and will be able to do a scientific evaluation of the data.

Kadi and Wiesing pointed out repeatedly - and rightly - that the most important information for affected couples, i.e., the probability that an initi- 
ated therapy will be brought to a successful conclusion with the birth of a child, cannot be clearly established based on the data published by the D.I.R. But this is due to a number of facts:

1. The documenting centers do not fully and completely record the course of all pregnancies which occur. This is regrettable but this already prompted the Board of the D.I.R in 2013 to launch a motivating campaign with the aim of improving the quality of data collection. Among other things, a special evaluation published in the annual D.I.R report for 2013 [2] and a number of different lecture events increased members' awareness of the importance of recording these meaningful parameters; in addition, compared to previous years members received more frequent requests earlier on to export their data on pregnancy outcomes. Centers with below average numbers of reported pregnancy outcomes were specifically asked to improve their reporting. This quality initiative has already begun to bear fruit: compared to the year 2012 (the mean percentage of pregnancy outcomes reported in 2012 was 84.9\%), significantly more pregnancy outcomes were documented in 2013 (93.4\%). This means that, within the space of just one year, the so-called "lost-to-follow-up rate" more than halved, decreasing from 15.1 to $6.6 \%$ [3].

2. To be able to calculate the actual rate of live births for every initiated treatment cycle, all oocytes obtained in the course of a procedure would have to be followed up until transfer and each oocyte would have to be matched to the respective retrieval procedure. At oocyte retrieval, more oocytes are usually collected and fertilized than are transferred to the patient in a single session. These spare fertilized oocytes are usually cryopreserved at the pronuclear stage of development, allowing them to be thawed and transferred during a later cycle of treatment. This means that several transfer cycles may be carried out after a single oocyte retrieval procedure, leading in some cases to the time-delayed birth of several siblings, all of which came from the same single oocyte retrieval procedure. Up to now, the D.I.R was not able to evaluate these data as the assignment of transferred embryos to a specific retrieval cycle was technically impossible. This was one of several factors which already prompted the D.I.R in 2012 to fundamentally revise the software used for data collection and reporting and triggered the decision to modernize the data structure. The software used up to now, known as DIRdll, will be replaced by modern data capture architecture, which will allow this question to be answered for the first time.

The fact that not all recorded cycles are entered prospectively has been known for quite some time. It has been the subject of an awareness campaign by the Board of the D.I.R since 2013 which employs a number of different measures to motivate the members of the D.I.R to improve the quality of their documentation. The authors of the article assert that "it cannot be precluded that all data is only entered after some delay", indicating that this would allow non-prospective procedures to be entered retrospectively as prospective procedures. We believe that this allegation is wholly without foundation. In the case of non-prospective cycles it is clear that we are looking at a problem arising from process workflows during the organization of treatment cycles (in other words, there is a problem with the quality of the documentation) and not at a deliberate attempt at deception. Why would a center which took the decision after the D.I.R was incorporated in 2009 to voluntarily report its anonymized data and to pay for this out of its own pocket invest a not insignificant amount of time and energy in laboriously manipulating and corrupting data during data en- try? The Board of the D.I.R considers this to be a completely unfounded insinuation which it strongly repudiates.

The authors of the article repeatedly blame the D.I.R for the fact that non-prospective data are also included, even though the "(proposed) guideline on the implementation of assisted reproductive technologies (German Medical Association 2006)" [4] specified that "data should only be collected prospectively". It should first be noted that the cited (proposed) guideline is not legally binding; it will only be incorporated in medical regulations if it is included in the professional code of conduct of the respective medical association of the federal state responsible for the individual IVF center. Hardly any medical association of a federal state in Germany has adopted the (proposed) guideline unchanged or incorporated it in their medical regulations; either parts of it were modified or the respective medical association (for example, the Medical Association of Berlin) did not adopt the (proposed) guideline at all. Moreover, on its homepage the German Medical Association has even added a qualifier on the "(model) guideline of the German Medical Association on the implementation of assisted reproduction (German Medical Association 2006)" as follows: "This guideline has not been adapted to the current legal situation and/or it no longer reflects the current state of knowledge in medical science and technology. It can therefore only provide specialists with information if persons are aware of the relevant changes in the legal situation and the changes in the state of knowledge in medical science and technology." [5]. Consequently, the authors' reference to this guideline is neither applicable nor expedient. With regard to content, the D.I.R does indeed face a dilemma as it must decide whether only prospective data should be published or whether non-prospective data should also be included. There can be no doubt that if the focus were only on the quality of the documentation, it would be preferable if all data were recorded exclusively prospectively. On the other hand, the D.I.R has set itself the goal of collecting the real data for all treatment cycles, evaluating it scientifically and making it publicly available, in order to specifically reflect the reality of IVF, ICSI and cryo transfer procedures in Germany. That is why we also took the deliberate decision to publish and evaluate data which were not recorded prospectively. It should be noted that these evaluations were also explicitly identified as such, to allow readers to interpret the results themselves.

Kadi and Wiesing point out that the D.I.R provides "no information $[. .$.$] on the success rates for individual centers"; instead,$ although the D.I.R does have the data, it only publishes national data. This criticism is as old as the publications of the D.I.R. The Board, the Board of Trustees and the office of the D.I.R already weighed in on this issue in the annual report for 2007 (i.e., long before the D.I.R was incorporated as a registered association, at a time when the D.I.R was still under the aegis of the Medical Association of Schleswig-Holstein):

"Why can't you find statistics on the individual success rates of every single IVF center in Germany in the annual report of the D.I.R? The notion seems both tempting and reasonable. It would be so nice if you could simply take the annual report of the German IVF register, look up the IVF centers in your region, and read up about their 'success rates'. Of course, you would then opt for the center with the highest reported pregnancy rates. After all, you would want the best physicians to treat you. A couple might be happy to accept a longer distance to travel if, for example, the pregnancy rates are higher in another German federal state. 
Although this may sound simple, matters are unfortunately not quite so simple. Quite apart from the fact that comparative advertising is prohibited to physicians in Germany, such a 'Top of the Pops' list or 'league table' would have serious secondary effects. It would lead to treating physicians taking great care to treat only those couples with a positive prognosis. Other couples could potentially be excluded from treatment because their prospects of success would be considered too low, which could jeopardize the center's good position in the 'league table'. The pressures of such competition could also negatively affect the quality and honesty of the documented data. The distortion triggered by a 'league table' of this type would be serious and would ultimately be to the detriment of patients.

What the German IVF Register has been doing for many years is now considered exemplary, also by international standards: it offers a clear picture of the situation in Germany and reflects current standards in Germany. The range of outcomes is shown openly but without naming specific centers. It is an invitation to you, as patients, to ask your treating physician, your treating IVF center about their success rates. That is the only place you will receive instructive explanations and the information which you need to understand why the outcomes of the center are what they are. This is the only way that will allow you to act as an autonomous patient and make a well informed decision." [6].

The British HFEA, which the authors have cited several times as an example of a state-run regulatory body with a compulsory duty to report data on procedures, takes a different approach here [7]. But it is questionable to what extent the quality of the collected data realistically reflects the conditions there. At any rate the data collected there is definitely not prospective, while in the D.I.R at least $87.08 \%$ of the documented treatment cycles fulfill this criterion [8]. Moreover, the HFEA also does not show the individual data of affected couples (number of oocytes obtained, number and quality of embryos, cryopreservation yes/ no, number of cryopreserved pronuclei/embryos, cumulative pregnancy rate/rate of live births per oocyte retrieval procedure/ per initiated treatment cycle). In our view, couples should have a proper discussion with the fertility doctors treating them to obtain a realistic assessment of the probability of success in their individual case. It is better if this information is obtained during a doctor-patient discussion rather than from an uncritical list of figures and it cannot be provided by either the D.I.R nor by a state-run institution such as the HFEA.

Kadi and Wiesing maintain that "the presentation of results [in the annual report of the D.I.R, Author's Note] is completely unsuitable for non-specialists as it is too complicated. The summary for patients, published for the first time in 2015, is too short and, in addition, it is uncritical." As the D.I.R is accessible both to non-specialists and to physicians, a compromise will of course be necessary. But several years ago, the D.I.R attempted to summarize the results in a manner comprehensible to non-specialists on 4 printed pages in the D.I.R annual report. The annual report for 2007 already considered and answered questions such as "What are the prospects in Germany of becoming pregnant or giving birth following a procedure with extracorporeal fertilization [...]?", "What are the risks during childbirth following extracorporeal fertilization (IVF or ICSI) with regard to multiple pregnancy or multiple births?", "Do the success rates of IVF/ICSI therapy vary for women depending on age?", "Does the number of transferred embryos affect the probability of success of IVF/ICSI treatment?" and "To what extent does the reason for carrying out the proce- dure (indication) affect the success rate?" [6]. This seems to have escaped Kadi and Wiesing. In fact, the summary cited by the authors, which apparently first appeared in 2015 and which was additionally considered too short and uncritical, did not merely aim to inform patients but primarily aimed to provide journalists with a short and concise description of certain key facts.

Nevertheless, the D.I.R accepts the criticism and will be presenting up-to-date information relevant for patients in its next annual report in a manner comprehensible for non-specialists.

Finally, we would like to quote from the book published to mark the 10th anniversary of the D.I.R, in which Mr. Dahncke, the developer of the original data structure of the German IVF Register at the Medical Association of Schleswig-Holstein, summarized the developments at the time. The current Board of the D.I.R would also like to take this opportunity to once again thank $\mathrm{Mr}$. Dahncke for his consistently constructive work. The summary hits the nail on the head and, in our opinion, still holds true today after almost 20 years of data collection by the D.I.R: " 10 years ago the Board of Trustees of the DIR defined the goals. The path was not always easy; progress was not always discernible at some stages; there was an impression that matters had stalled. When we look back now, we see a very long, not always straightforward but ultimately successful, path towards the goal of optimal data collection. The path may never reach the goal but it will constantly come closer." [1].

In our opinion, it is highly questionable whether a state-run body - which Kadi and Wiesing consider to be inevitable - or an institute under state supervision would handle the task better. On the contrary, the work of the D.I.R as a scientific register and the quality assurance initiative of the medical associations of the German federal states (QSRepromed) should be jointly capable of dealing with the task itself, working on behalf of physicians, patients, journalists and interested non-specialists. It has been demonstrated in the past, for example in France, that medical self-government and the chartered medical profession can achieve more than state-imposed compulsory administration.

\section{Conflict of Interest}

$\nabla$

The authors state that, besides being elected members of the board of directors of the Deutsches IVF-Register, they do not have any conflict of interest.

\section{References}

1 Felberbaum $R$, Bühler J, van der Ven $H$. Vorwort. In: Felberbaum $R$, Bühler J, van der Ven H, Hrsg. Das Deutsche IVF-Register 1996-2006, 10 Jahre Reproduktionsmedizin in Deutschland. Heidelberg: Springer Medizin Verlag; 2007

2 Deutsches IVF-Register. Jahrbuch 2013. J Reproduktionsmed Endokrinol 2014; 11: 36-37

3 Deutsches IVF-Register. Jahrbuch 2014. J Reproduktionsmed Endokrinol 2015; 12: 38-39

4 Bundesärztekammer. Richtlinien zur Durchführung der assistierten Reproduktion. Deutsches Ärzteblatt 2006; 103: 1392-1403

5 Bundesärztekammer. Assistierte Reproduktion. Online: http://www. bundesaerztekammer.de/richtlinien/richtlinien/assistiertereproduktion/; last access: 12.05 .2016

6 Deutsches IVF-Register. Jahrbuch 2007. Online: http://www.deutschesivf-register.de/perch/resources/downloads/dirjahrbuch2007.pdf; last access: 12.05 .2016

7 Human Fertilisation and Embryology Authority. Homepage. Online: http://www.hfea.gov.uk; Stand: 12.05 .2016

8 Deutsches IVF-Register. Jahrbuch 2014. J Reproduktionsmed Endokrinol 2015; 12: 11 